\title{
Construção participativa de instrumento de política pública para gestão e acesso à informação
}

\section{Gustavo Henrique de Araújo Freire}

\author{
Doutor em Ciência da Informação. \\ Pesquisador do CNPq. Professor do \\ Programa de Pós-Graduação em Ciência \\ da Informação da UFPB.
}

Apresenta o marco teórico para políticas públicas de informação do projeto de pesquisa do CNPq "Entre o Global e o Local: construção participativa de instrumento de política pública para gestão e acesso à informação" e sua proposta metodológica. Define "política de informação" e sua correlação com gestão da informação. Descreve a metodologia do projeto, na qual serão reunidas as propostas da pesquisa-ação e da pesquisaparticipante, de modo a proporcionar maior integração do projeto dos pesquisadores com os participantes da comunidade.

Palavras-chave: Política de informação; Gestão da informação; Acesso à informação; Ciência da Informação.

\section{Participative construction of a public policy instrument for information management and access}

The article shows the theoretical foundation and methodological proposal concerning public information policies associated to the research project entitled "Between the Global and the Local: The Participative Construction of a Public Policy Instrument for Information Management and Access" sponsored by CNPq. The article defines "Information policy" and its relationship with "Information management". The project methodology is described with the proposals of the action-participant research in a way to promote a better integration of the researchers with members of the community 
Keywords: Information policy; Information management; Information access; Information literacy; Social responsibility; Information science

\section{Introdução}

O presente trabalho tem a finalidade de registrar o referencial teórico para a nossa reflexão sobre políticas de informação. A idéia surge da necessidade de uma ação de informação pública com vistas à inclusão digital e social. É assim que a Ciência da Informação incorpora à sua definição a noção de uma ação de informação, que remete seus atores sociais aos contextos onde esta ocorre.

No nosso escopo, trata-se de promover o "conhecimento em ação" (WERSIG, 1993) na Ciência da Informação, de modo a intervir sobre o regime de informação da Comunidade Santa Clara, PB. O trabalho se realiza no âmbito do Grupo de Pesquisa Informação e Inclusão Social, do qual fazemos parte ${ }^{1}$.

Esperamos contribuir para a discussão de políticas públicas de acesso livre à informação e inclusão digital, que por sua vez pode criar oportunidades de inclusão social em pequenos municípios brasileiros. Inclusão na sociedade da informação se dá não somente pelo acesso ao meio digital como também, especialmente, pela oportunidade de promover nos participantes a competência intelectual de refletir sobre seu espaço e papel nesta sociedade que todos estamos ajudando a construir.

\section{Contexto}

A inclusão digital refere-se ao processo de inserção na sociedade da informação através das tecnologias de informação. O Brasil tem $89 \%$ de excluídos digitais, que perdem a chance de ascensão social. Uma contradição em um país que disponibiliza $72 \%$ dos serviços do governo federal através da rede mundial de computadores (ASSOCIAÇÃO BRASILEIRA DE EDUCAÇÃO À DISTÂNCIA - ABED, 2006).

As ações para inclusão digital tornaram-se especialmente relevantes à medida que a Internet no Brasil vai se firmando cada vez mais como um importante canal de serviços e mídia, não somente para os integrantes das classes $A$ e $B$ como, também, para as $C, D$ e até a $E^{2}$. Entretanto, é consenso que os elementos necessários para inclusão não devem contemplar apenas o acesso físico à infra-estrutura e à conexão em rede e

\footnotetext{
Ver em: http://dgp.cnpq.br/buscaoperacionall, a discussão se insere no contexto do Projeto Janelas da Cultura Local, que está sendo desenvolvido em Quissamã, RJ, com apoio do CNPq e em parceria com a Secretaria Municipal de Educação. As idéias que norteiam o presente texto foram discutidas com as pesquisadoras Isa Maria Freire e Carmelita do Espírito Santo, em Seminário de Pesquisa do Projeto realizado no Rio de Janeiro, RJ, nos dias 22 e 23 de fevereiro de 2007.

De acordo com pesquisa do Ibope/NetRatings (outubro de 2006), o acesso à internet é proporcionalmente bem menor no caso das classes C (22\%), D e E (10\%), sendo a navegação em locais públicos mais freqüente: $47 \%$ dos internautas de classe $C$ navegam em locais públicos pagos e $19 \%$ em locais de acesso gratuito; nas classes D e E, o percentual sobe para $61 \%$ (pagos) e $28 \%$ (gratuitos). Segundo a pesquisa, entre os usuários de acessos públicos gratuitos, com freqüência de uma ou duas vezes por semana, $33 \%$ utilizam a web para fazer atividades escolares. Disponível em: <www.ibope.com.br>. Acesso em: 11 nov. 2008.
} 
computadores, mas também, e especialmente, a capacitação das pessoas para utilizar estes meios de comunicação da informação e, principalmente, para criar a "possibilidade de uma incorporação ativa no processo todo de produção, compartilhamento e criação cultural", os chamados "conteúdos" (LAZARTE, 2000, p.51). O autor sugere integrar essa "possibilidade" às condições locais existentes, em termos tanto de suas organizações quanto de seus referenciais culturais: centros de produção, criação e compartilhamento cultural (e de acesso à rede) devem estar integrados a associações comunitárias, centros religiosos, igrejas etc. ${ }^{3}$

Por sua vez, Araújo (2001) destaca que o verdadeiro desafio será criar tecnologias, produzir tecnologias intelectuais e sistemas mais eficazes, não só para gerenciar informação como, também, para facilitar ao ser humano a transformação da informação em conhecimento e conseqüentemente em ação na sociedade. Isso dependeria não somente de nossa ação no mundo, mas, especialmente, da nossa conscientização sobre o poder transformador da informação,...

[pois] se a informação é a mais poderosa força de transformação do homem, [o] poder da informação, aliado aos modernos meios de comunicação de massa, tem capacidade ilimitada de transformar culturalmente o homem, a sociedade e a própria humanidade como um todo (ARAUJO, 1994. p.84).

As ações voltadas para promover a "inclusão digital" emergem no contexto dos Programas Sociedade da Informação, propostos por diversos países, configurando-se como uma das idéias-chave que perpassam ações, estudos e pesquisas nos mais diferentes campos do saber. No Brasil, as bases para inclusão na Sociedade da Informação estão formuladas no Livro Verde da Sociedade da Informação (BRASIL, 2000). No contexto brasileiro observa-se que ainda há a necessidade de "um marco teórico mais sólido para orientar nossas políticas públicas e a implementação das infra-estruturas de acesso à informação no Brasil", como alerta Miranda (2006, p. 23).

Neste projeto, complementamos esta perspectiva com a proposição de uma abordagem participativa, uma "pesquisa-ação" onde pesquisadores e comunidades trabalhem juntos, compartilhando saberes com o propósito de criar as diretrizes para uma política de informação local no regime de informação global. É assim que o projeto se insere no contexto da necessidade da construção participativa de uma política pública para a gestão de recursos de informação em nível local, com vistas à inclusão digital e social. De modo que os participantes possam ter não somente o acesso livre e democrático a fontes de informação relevantes na Internet, mas, especialmente, também a oportunidade de produzir conteúdos digitais sobre a cultura local.

\footnotetext{
${ }^{3}$ O projeto Janelas da cultura local acrescenta as escolas.
} 


\section{Responsabilidade social e ação de informação}

Nossas premissas básicas são a responsabilidade social da Ciência da Informação (WERSIG; NEVELING, 1975; FREIRE, I. M, 2001) e sua relação intrínseca com a tecnologia da informação (SARACEVIC, 1995; PINHEIRO, 1997; FREIRE, G. H. A., 2004), que se manifestam neste projeto através do desenvolvimento de competências em informação numa comunidade.

Para González de Gómez (1999, p. 69), a gestão da informação envolve "o planejamento, instrumentalização, atribuição de recursos e competências, acompanhamento e avaliação das ações de informação e seus desdobramentos em sistemas, serviços e produtos". Nesta perspectiva, a gestão estabelece a mediação entre as políticas de informação de um setor e a ação informada dos atores sociais envolvidos, sejam eles "o Estado, o Governo, ou comunidades usuárias de bens e serviços de informação ou atingidas em seus processos cognitivos e deliberativos pela disponibilização ou omissão de informações" (GONZÁLEZ DE GÓMEZ, 1999, p.69).

Segundo Marchiori (2002, p. 75), a gestão da informação é abordada na perspectiva de Ponjuan Dante como um "conjunto de processos que englobam atividades de planejamento, organização, direção, distribuição e controle de recursos de qualquer natureza, visando à racionalização e à efetividade de determinado sistema, produto ou serviço". Nesta perspectiva, a gestão de recursos informacionais pode fazer a diferença de modo a favorecer o acesso a serviços e aplicações das tecnologias digitais de informação e comunicação. Por isso mesmo, Isa Maria Freire (2006) aponta que a democratização do acesso às tecnologias digitais e intelectuais de informação e comunicação deveria ser vista como elemento fundamental nas políticas públicas de inclusão social.

No âmbito da Ciência da Informação no Brasil, a temática das políticas de informação encontra-se fundamentada, principalmente, nos estudos de González de Gómez. A autora define a Ciência da Informação como uma "disciplina que estuda fenômenos, processos, construções, sistemas, redes e artefatos de informação"(GONZÁLEZ DE GÓMEZ, 2004, p. 61). Nesta perspectiva, a informação é definida como "ações de informação, que remetem seus atores aos contextos onde estas ocorrem" (GONZÁLEZ DE GÓMEZ, 2004, p.61). A informação enquanto Ação de Informação refere-se a um conjunto de estratos heterogêneos $e$ articulados, que se manifestam através de três modalidades:

- ação de mediação: a ação fica atrelada aos fins e orientação de uma outra ação;

- ação formativa: a ação está orientada à informação não como um meio, mas como sua finalização;

- ação relacional: a ação busca intervir em uma outra ação para obter direção e fins (GONZALEZ DE GOMEZ, 2004, p. 61). 
Nesse contexto, as ações de pesquisa e as ações de informação integrarão um mesmo domínio de orientações estratégicas e, em conseqüência, a política e a gestão da informação formarão parte do mesmo plano decisional e prospectivo ao qual pertencem a política e a gestão da ciência e da tecnologia (C\&T).

Segundo Japiassu e Marcondes (1996, p.215), o termo política refere-se a "tudo aquilo que diz respeito ao cidadão, aos governos e aos negócios públicos". A natureza normativa da política estabelece "os critérios da justiça e do bom governo, e examinado as condições sob as quais o homem pode atingir a felicidade (o bem-estar) na sociedade, em sua existência coletiva" (JAPIASSU e MARCONDES, 1996, p.215). Pode-se perceber que tanto o conceito de informação quanto o de política possuem o mesmo sentido de ordem e regulação que, reunidos, formam o conceito de "políticas de informação": conjunto de leis, regulamentos e políticas que estimulam ou regulam a geração, o uso, o armazenamento e a comunicação de informação.

Como política pública, a política de informação assenta-se sobre "interesses e metas políticas e burocráticas, não necessariamente congruentes, manifestando-se para além do aparato governamental" (BRANCO, 2006, p. 87). Nesse sentido, a expressão de uma política de informação ultrapassa o campo formal das leis e regulamentos, pois também engloba as práticas e ações informais de um determinado contexto "em que se misturam pessoas, instituições e interesses, cujas manifestações nem sempre se revelam por mecanismos formais" (BRANCO, 2006, p. 89). A política de informação deve ser um instrumento regulador entre a sociedade e os avanços científicos e tecnológicos, e deve atuar de forma participativa. Assim praticada, segundo Silva (1991), ela contribuirá para a melhoria do nível educacional, cultural e político, elementos básicos para o exercício pleno da cidadania.

Uma política de informação pode ser elaborada sob duas abordagens: a básica e a específica. A primeira refere-se aos aspectos gerais da produção de informação, como aqueles ligados à tecnologia de informação, às telecomunicações e à política internacional, dentre outros. Já a política específica de informação, conforme Branco (2006), diz respeito aos aspectos característicos de determinado setor de atividade como, por exemplo, uma política para gestão da informação que contemple a produção de conteúdos de identidade cultural e o acesso livre a fontes de informação relevantes na Internet. Neste caso, a política de informação estará voltada para objetivos e metas específicos, que the darão contornos próprios e inerentes ao respectivo espaço ou regime de informação.

Todavia, as propostas de políticas públicas de informação no Brasil ainda carecem de articulação entre as esferas cultural, educacional e de comunicação, que se entrelaçam com as relações sócio-econômicas. Neste ambiente, as políticas públicas necessitam da convergência de mídias, de tecnologias e de serviços. É nesse quadro que podem fazer a diferença, favorecendo o crescimento de uma sociedade da informação onde todos tenham "acesso a uma quota parte mínima dos novos serviços e 
aplicações" das tecnologias digitais de informação e comunicação (ASSMANN, 2000 citado por FREIRE, I. M., 2005, p.15).

Segundo estudo realizado por Schwarzelmüller, Gesteira e Bulcão (2006), a maioria das ações, que se poderia chamar de políticas de informação no Brasil, foram formuladas para a informação científica e tecnológica.

As políticas de informação favoreciam a comunidade científica, em detrimento da maioria da população. Nesse sentido, uma política de informação deve ser flexível o bastante para permitir a participação dos mais diversos setores da sociedade brasileira.

A nosso ver, nesse contexto cabe à Ciência da Informação desenvolver o embasamento teórico para proposição e discussão de ações de informação que contribuam para promover políticas de informação a serem utilizadas como instrumentos de gestão de recursos de informação.

\section{Políticas de informação em um regime de informação}

Para González de Gómez (2002, p. 35), o "escopo e a abrangência dos estudos em torno da política de informação se multiplicam e se fragmentam" em todas as abordagens da Ciência da Informação. Neste enfoque, definir políticas de informação implica em ultrapassar esse contexto interdisciplinar da Ciência. Por isso, a autora propõe-se utilizar um conceito de política de informação que "tratará de resgatar a amplidão e complexidade do campo, permitindo a consideração das macro e micropolíticas, bem como das políticas locais, regionais, nacionais e globais" (GONZÁLEZ DE GÓMEZ, 2002, p.67). Essa abordagem de políticas de informação utiliza como base o conceito de regime de informação, o qual é definido como

Conjunto mais ou menos estável de redes neurocomputacionais formais e informais nas quais informações podem ser geradas, organizadas e transferidas de diferentes produtores, através de muitos e diversos meios, canais e organizações, a diferentes destinatários ou receptores, sejam estes usuários específicos ou públicos amplos (GONZALEZ DE GOMEZ, 2002, p. 69).

No conceito de regime de informação, a relação entre a política e a informação ficaria em observação, permitindo incluir tanto as políticas tácitas e indiretas quanto as explícitas e públicas, micro e macropolíticas, assim como permitiria articular, "em um plexo de relações por vezes indiscerníveis, as políticas de comunicação, cultura e informação" (GONZÁLEZ DE GÓMEZ, 2002, p.70).

O conceito de regime de informação foi criado por Frohmann (1995) para caracterizar o fluxo de informação no campo de atuação das políticas de informação, utilizando como base a teoria Ator-Rede de Bruno Latour ${ }^{4}$.

Na teoria ator-rede, de Latour, a noção de rede refere-se a fluxos, circulações, alianças, movimentos, em vez de remeter a uma entidade fixa. Uma rede de atores não é redutível a um ator sozinho, nem a uma rede; ela é composta de séries heterogêneas de elementos, animados e inanimados, conectados, 
Todavia, o conceito de regime de informação que adotamos é o desenvolvido por González de Gómez (1999), com base no conceito de "dispositivo" formulado por Michael Foucault, aqui compreendido como "instrumento" ou "tecnologia intelectual" (FREIRE, G. H. A., 1998; 2004).

Nesta perspectiva, os dispositivos são os lugares materiais ou imateriais nos quais se inscrevem (necessariamente) os textos (despachos de agências, jornal, livro, rádio, televisão, etc). O dispositivo não é um 'suporte', mas uma matriz que impõe suas formas aos textos (uma conversação 'informal', por exemplo, se inscreve nas formas da conversação, como variante de um paradigma). Na questão informacional, um dispositivo permite a leitura de relações entre elementos heterogêneos, discursivos, tecnológicos, econômicos e culturais. Assim, pode ser indicado para a análise de micropolíticas ou de figuras descentralizadas e locais de políticas de informação. Neste enfoque, González de Gómez considera "o conjunto dos produtos e serviços de informação e das ações de transferência de informação como momentos de um dispositivo de informação" (GONZÁLEZ DE GÓMEZ, 1999 , p.63). Isto quer dizer que um dispositivo de informação fundamenta-se na estrutura de dispositivos anteriores de informação. Assim,

... a escrita não anula mas reinscreve a comunicação oral. A informação eletrônica reinscreve quase totalmente os procedimentos, instrumentos e recursos da escrita. [Neste sentido] as práticas dos atores sociais tendem a preservar ou modificar os dispositivos coletivos de informação e, ao mesmo tempo, os dispositivos de informação preexistentes impõem condições estruturais às novas estratégias de informação (GONZÁLEZ DE GÓMEZ, 1999, p. 63).

A autora propõe quatro definições de políticas de informação no contexto do regime de informação, quais sejam: uma política de informação pode ser considerada como "um conjunto de ações e decisões orientadas a preservar e a reproduzir, ou a mudar e substituir um Regime de Informação, e podem ser tanto políticas tácitas ou explícitas, micro ou macropolíticas" (GONZÁLEZ DE GÓMEZ, 1999, p. 63). Uma segunda definição é direcionada para diferenciar gestão de política de informação:

Falamos de Políticas de Informação quando, tratando-se de uma questão colocada num domínio coletivo de ação, existem conflitos entre as diferentes formulações de objetivos, planos, atores e recursos atribuídos às ações do domínio, e em conseqüência, com respeito ao alcance, às prioridades e às metas das ações de informação, de modo que aqueles

agenciados. Por um lado, a rede de atores deve ser diferenciada dos tradicionais atores da sociologia, uma categoria que exclui qualquer componente não-humano. Por outro, a rede também não pode ser confundida com um tipo de vínculo que liga, de modo previsível, elementos estáveis e perfeitamente definidos, porque as entidades das quais ela é composta, sejam elas naturais ou sociais, podem a qualquer momento redefinir sua identidade e suas mútuas relações, trazendo novos elementos para a rede. Assim, uma rede de atores é simultaneamente um ator, cuja atividade consiste em fazer alianças com novos elementos, e uma rede capaz de redefinir e transformar seus componentes. 
conflitos não poderiam ser equacionados ou resolvidos por meios técnicos ou instrumentais e requerem a reformulação deliberativa de princípios, fins e regras para a concretização de planos coletivos e coordenados de ação, ou a mudança das relações de força dos atores envolvidos (GONZÁLEZ DE GÓMEZ, 1999, p.71).

$\mathrm{Na}$ terceira definição, as políticas são abordadas como orientações com relação a fins, valores e objetivos das políticas de informação, designando "as figuras decisionais e normativas do que seja desejável e prioritário para um sujeito coletivo (organização, regiões, Estado Nacional etc.), acerca da geração, circulação, tratamento e uso da informação" (GONZÁLEZ DE GÓMEZ, 1999, p.71).

Na quarta e última definição, as políticas atuam como uma "ação dirigida a consolidar a autonomia informacional dos sujeitos coletivos", considerando que:

A constituição dos universos de informação parte sempre do 'nós' de um sujeito situado, localizado, territorializado, para o qual algo faz ou não faz sentido como informação. Em cada contexto histórico, em cada espaço de ação coletiva, existe um saber local, um sentimento territorializado ou um desejo do que seja um bem coletivo, que formam parte das razões bem fundadas para priorizar, justificar, gerar ou aderir a um valor de informação (GONZÁLEZ DE GÓMEZ, 1999, p.71)

Implica dizer aqui que, embora a Sociedade da Informação seja um fenômeno mundial, uma política de informação deve privilegiar, antes de mais nada, a estrutura informacional do local, visando a sua inserção no global, pois...

[...] a partir do potencial integrativo do novo padrão tecnológico, o local redefine-se, ganhando em densidade comunicacional, informacional e técnica no âmbito das redes informacionais que se estabelecem em escala planetária. ... a dimensão cultural do local atua na globalidade como um fio invisível que vincula os indivíduos ao espaço, marcando uma certa idéia de diferença ou de distinção entre comunidades. Assim, o local constitui-se em suporte e condição para as relações globais. É nele que a globalização se expressa concretamente e assume especificidades (ALBAGLI, 1999, p.186-187).

Assim, qualquer que seja a forma de proporcionar o acesso a redes de informação global, como a Internet, por exemplo, esta deverá estar integrada às condições locais existentes, tanto em termos de suas organizações quanto de seus referenciais culturais, e a produção cultural deve estar centrada nos valores significativos locais. Para González de Gómez (2003), a... 
[...] sociedade da informação poderia ser entendida como aquela em que o regime de informação caracteriza e condiciona todos os outros regimes sociais, econômicos, culturais, das comunidades e do Estado. Nesse sentido, a centralidade da comunicação e da informação produziria a maior dispersão das questões políticas da informação, perpassada e interceptada por todas as outras políticas: as públicas e as informais, as tácitas e as explícitas, as diretas ou indiretas (GONZÁLEZ DE GÓMEZ, 2003, p.61).

A informação seria, então, o elemento que unificaria a "dispersão" das questões relacionadas às políticas da informação presentes em cada um dos regimes de informação, independente de serem políticas "públicas, informais, tácitas, explícitas, diretas ou indiretas" (GONZÁLEZ DE GÓMEZ, 2003, p.61).

De acordo com o exposto, a gestão de recursos de informação, visando à inclusão digital através de competências em tecnologias digitais e intelectuais de informação e comunicação, carece de instrumentos de política pública que possam orientar as ações necessárias para incluir comunidades na sociedade da informação. Nesta pesquisa, diremos que existem políticas de informação para inclusão digital, porém estas se encontram dispersas nos diversos regimes de informação que compõem a sociedade brasileira.

Neste sentido, defendemos a tese de que há necessidade de criação de instrumentos de gestão que contemplem as políticas públicas de informação voltadas para inclusão digital e social. E é nosso propósito, neste projeto, fazê-lo com a participação daqueles que serão seus maiores beneficiários - no caso, a comunidade de Santa Clara, em João Pessoa, $\mathrm{PB}$.

\section{Pesquisa-ação para desenvolvimento do projeto}

A escolha da pesquisa-ação traduz a tentativa de abordar a comunicação da informação como ação transformadora, no sentido que Ihe atribui Araújo (1994), criando espaço para intervenção empírica em uma dada situação. A pesquisa-ação supõe uma participação e uma forma de ação planejada que atinjam os vários elementos das atividades humanas - diretamente relacionadas à presente proposta, na medida em que viabilizam a ação coletiva pautada pela resolução de problemas e por objetivos de transformação.

Segundo Thiollent, a pesquisa-ação "consiste essencialmente em acoplar pesquisa e ação em um processo no qual os atores implicados participam, junto com os pesquisadores, para chegarem interativamente a elucidar a realidade em que estão inseridos" (THIOLLENT, 1997, p.15). Nessa perspectiva, entende-se por "ator" qualquer grupo de pessoas dispondo de certa capacidade de ação coletiva consciente em um contexto social delimitado, podendo designar tanto os grupos informantes no meio de uma organização, quanto os grupos formalmente constituídos. E a 
"participação" é encarada como propriedade emergente do processo e não como um a priori.

A construção participativa de um instrumento, contendo diretrizes para a formação de uma política pública de gestão de recursos de informação, em âmbito local, será o eixo motivacional e operatório da pesquisa. Para a construção desse instrumento, com a participação da comunidade de Santa Clara, optamos por utilizar a metodologia da pesquisa-participante ${ }^{5}$, utilizada de forma inovadora por Freire e Espírito Santo em suas respectivas dissertações de Mestrado em Ciência da Informação ${ }^{6}$.

O processo envolve contato permanente entre os participantes da pesquisa (pesquisadores e usuários), sendo que o primeiro momento é dedicado ao conhecimento preliminar da realidade, de modo a identificar o que Goldmann (1970) denomina "informação prévia". Desta ação resulta a formação de um grupo de trabalho que, no segundo momento, identifica, na comunidade, os "temas geradores" do conteúdo do instrumento. Nesse sentido, ela oferece a oportunidade para que a comunidade possa participar da análise da sua própria realidade. Assim, o regime de informação pode ser visto como uma abordagem "que poderia resolver a tensão contínua entre o processo de geração de conhecimento e o uso deste conhecimento, entre o mundo acadêmico e o real entre intelectuais e trabalhadores, entre ciência e vida" (DEMO, 1986, p.126).

\subsection{Campo empírico da pesquisa}

Como mencionado, o campo empírico da pesquisa será a Comunidade Santa clara, que faz parte do Conjunto Habitacional Castelo Branco I. Trata-se de uma comunidade carente circunvizinha à Universidade Federal da Paraíba. O Departamento de Biblioteconomia e Documentação da UFPB já tem uma história de atuação junto a esta comunidade através de Projeto de Extensão, que inicia agora a sua sétima edição. Em uma de suas versões, contribuiu para a criação da ACMCSC.

É importante ressaltar a importância das atividades de Extensão da Universidade como forma de devolver para a sociedade, principalmente para os grupos menos favorecidos, os recursos investidos na pesquisa e no ensino. Um dos objetivos do Projeto de Extensão "Resgatando a cidadania; brincando de biblioteca, conte uma história, construa um acervo" (sétima versão) é "estudar a viabilidade da implantação de um Tele Centro (inclusão digital) para atender as comunidades circunvizinhas à UFPB" (UNIVERSIDADE FEDERAL DA PARAÍBA - UFPB, 2007).

Neste sentido, ao escolher a comunidade Santa Clara, o nosso Projeto vem unir a pesquisa e a extensão para construir, de forma

5 O termo "pesquisa participante", criado por pesquisadores americanos e europeus da área das Ciências Sociais, envolvidos com projetos de intercâmbio com países do Terceiro Mundo, em geral é utilizado para denominar o esforço para desenvolver práticas de pesquisa que incorporem grupos excluídos, econômica e politicamente.

6 Ambas no Programa de Pós-Graduação em Ciência da Informação. Convênio CNPq/IBICT UFRJ/ECO. 
participativa, um instrumento com diretrizes para a formação de uma política pública de gestão e acesso a recursos de informação em âmbito local. Esta "ação de informação" se insere na abordagem da responsabilidade social da Ciência da Informação, no caso a de incluir as pessoas dessa comunidade (crianças, adolescentes, jovens, adultos, idosos) na sociedade da informação.

\section{Referências}

ASSOCIAÇÃO BRASILEIRA DE EDUCAÇÃO A DISTÂNCIA - ABED. Exclusão digital. $2006 . \quad$ Disponível em: $<$ www.abed.org.br/publique/cgi/cgilua.exe/sys/start.htm?sid=14\&infoid= 433>. Acesso em: 6 abr. 2008.

ALBAGLI, S. Globalização e espacialidade: o novo do local. In: ALBAGLI, S.; LASTRES, H. Globalização \& Inovação localizada: experiências de sistemas locais no Mercosul. Brasília: IBICT/MCT, 1999.

ARAUJO, V. M. R. H. Sistemas de recuperação da informação: nova abordagem teórico conceitual. 1994. Tese. (Doutorado em Comunicação e Cultura) - Universidade Federal do Rio de Janeiro, Escola de Comunicação, Rio de Janeiro, 1994.

Miséria informacional: o paradoxo da subinformação e superinformação. Inteligência Empresarial, n. 7, p. 5-12, abr. 2001.

ASSMANN, H. A metamorfose do aprender na sociedade da informação. Ciência da Informação, v. 29, n. 2, p. 7-15 2000 citado por FREIRE, G. H. A. Comunicação da informação em redes virtuais de aprendizagem. 2004. Tese. (Doutorado em Ciência da Informação) - Instituto Brasileiro de Informação em Ciência e Tecnologia - IBCT, Universidade Federal do Rio de Janeiro - UFRJ, Rio de Janeiro, 2004.

BRANCO, M. A. F. Política Nacional de Informação em Saúde no Brasil: um olhar alternativo. 2001. Tese (Doutorado em Medicina Social) - Instituto de Medicina Social, Universidade do Estado do Rio de Janeiro - UERJ, Rio de Janeiro, 2001.

BRASIL. Ministério da Ciência e Tecnologia. Sociedade da Informação no Brasil: Livro verde. Brasília: MCT, 2000. Disponível em: <www.socinfo.org.br/livro verde/>. Acesso em: 2 mar. 2008.

DEMO, $P$. Elementos metodológicos de pesquisa participante. In: BRANDÃO C.R. (Org.) Pesquisa participante. 6.ed. São Paulo: Brasiliense, 1986.

FREIRE, G. H. A. Comunicação da informação em redes virtuais de aprendizagem. 2004. Tese. (Doutorado em Ciência da Informação) Instituto Brasileiro de Informação em Ciência e Tecnologia - IBCT, Universidade Federal do Rio de Janeiro - UFRJ, Rio de Janeiro, 2004.

A construção de instrumento para comunicação de informação sobre saúde. Dissertação. 1998. Dissertação (Mestrado em Ciência da 
Informação) - Instituto Brasileiro de Informação em Ciência e Tecnologia - IBCT, Universidade Federal do Rio de Janeiro - UFRJ, Rio de Janeiro, 1998.

FREIRE, I. M. Janelas da cultura local: abrindo oportunidades para a inclusão digital. 2005. Disponível em: <http://www.isafreire.pro.br/CNPqProjetojanelas.pdf $>$. Acesso em: 4 maio. 2008. [Projeto CNPq.]

- Janelas da cultura local: abrindo oportunidades para a inclusão digital. Ciência da Informação, v. 35, n. 3, p. 227-235, 2006.

A responsabilidade social da ciência da informação e/ou O olhar da consciência possível sobre o campo científico. 2001. Tese. (Doutorado em Ciência da Informação) - Instituto Brasileiro de Informação em Ciência e Tecnologia - IBCT, Universidade Federal do Rio de Janeiro - UFRJ, Rio de Janeiro, 2001.

FROHMANN, B. Taking information policy beyond information science: aplplying the network theory. In: ANNUAL CONFERENCE FOR INFORMATION SCIENCE, 23., 7-10 Jun, 1995, Alberta, Canadá. Connectedness: information, systems, people, organizations. Alberta, Canadá: Canadian Association for Information Science, 1995.

GOLDMANN, L. Importância do conceito de consciência possível para a informação. In: COLÓQUIOS FILOSÓFICOS DE ROYAUMONT. O conceito de informação na ciência contemporânea. Rio de Janeiro: Paz e Terra, 1970.

GONZÁLEZ DE GÓMEZ, M. N. Novas fronteiras tecnológicas das ações de informação: questões e abordagens. Ciência da Informação, v.33 n.1, p. 55-67, 2004.

- As relações entre Ciência, Estado e Sociedade: um domínio de visibilidade para as questões da informação. Ciência da Informação, v.32 n.1, p. 60-76, 2003.

- Novos cenários políticos para a informação. Ciência da Informação, v.31, n.1, p. 27-40, 2002.

- Da política de informação ao papel da informação na política contemporânea. Revista Internacional de Estudos Políticos, v.1, n.1, p. 21-32, 1999.

JAPIASSÚ, H.; MARCONDEZ, D. Dicionário Básico de Filosofia. Rio de Janeiro: Jorge Zahar Editor, 1996.

LAZARTE, L. Ecologia cognitiva na sociedade da informação. Ciência da Informação, v.29, n. 2, p. 43-51, 2000.

MARCHIORI, P. Z. A ciência e a gestão da informação: compatibilidades no espaço profissional. Ciência da Informação, v.31, n.2, p. 72-79, 2002.

MIRANDA, A. Organização de conteúdos e identidade cultural. In INTEGRAR CONGRESSO INTERNACIONAL DE ARQUIVOS, BIBLIOTECAS, 
CENTROS DE DOCUMENTAÇÃO E MUSEUS, 2., 25-29 jun. 2006, São Paulo. Compartilhando o Conhecimento: o acesso sem fronteiras. Anais. São Paulo: Febab, 2006. Disponível em: <http://www.antoniomiranda.com.br/ciencia_informacao/organizacao_de _conteudos.html>. Acesso em: 20 abr. 2008.

PINHEIRO, L. V. R. A Ciência da Informação entre sombra e luz: domínio epistemológico e campo interdisciplinar. 1997. Tese. (Doutorado em Comunicação e Cultura) - Universidade Federal do Rio de Janeiro, Escola de Comunicação, Rio de Janeiro, 1997.

SARACEVIC, T. Interdisciplinary nature of information science. Ciência da Informação, v.24, n.1, p. 1-9, 1995.

SCHWARZELMÜLleR, A. R; GESTEIRA, I. A. L.; BULCÃO, M. Políticas públicas de informação no Brasil: Norte, Nordeste e Centro-Oeste. Disponível em: <http://dici.ibict.br/archive/>. Acesso em: 26 jul. 2006.

SILVA, T. E. Política de informação na pós-modernidade: reflexões sobre o caso do Brasil. Informação \& Sociedade: Estudos, João Pessoa, v. 1, n. 1, p. 8-13, 1991.

THIOLLENT, M. Metodologia da pesquisa-ação. 10.ed. São Paulo: Cortez, 2000

Pesquisa-Ação nas organizações. São Paulo: Atlas, 1997.

UNIVERSIDADE FEDERAL DA PARAÍBA - UFPB. Departamento de Ciência da Informação. Resgatando a cidadania: brincando de biblioteca, conte uma história construa um acervo. [João Pessoa: s.n.], 2007. [Projeto de extensão].

WERSIG, G. Information science: the study of postmodern knowledge usage. Information Processing \& Management, v.29, n.2, p. 262-284, 1993.

WERSIG, G., NEVELING, U. The phenomena of interest to information science. The Information Scientist. v.9, n.4, p. 173-191, 1975.

INSTITUTO BRASILEIRO DE OPINIÃO PÚBLICA E ESTATÍSTICA - IBOPE. Disponível em: <www.ibope.com.br>. Acesso em: 11 nov. 2008. 